\title{
Ventilation during Anesthesia: From Automatic Human Hand to Intelligent Machine!
}

\section{INTRODUCTION}

Manual ventilation during anesthesia and surgery, particularly in the prolonged procedures, is tiring to an anesthesiologist and adds an element of danger to a patient. In spite of advances in locoregional anesthesia and its widespread usage, general anesthesia with mechanical ventilation still holds the center stage in the intraoperative management of many surgical procedures. Less than a quarter-century ago, induction of anesthesia was mostly followed by paralysis using succinylcholine and endotracheal intubation. After recovery from succinylcholine, the patients were allowed to breathe spontaneously. If continued muscle relaxation was required, mechanical ventilation was manual with no monitoring whatsoever. An anesthetist was most often blissfully unaware of any changes. Needless to say, that the variations would be more with a tired and sleepy anesthetist at the head-end of the patient. Gone are those days of mechanical ventilation being heavily dependent on the "acquired automaticity" of the anesthetist's hands!

The venture of artificial ventilators into anesthesia practice began when surgeons started performing more extensive thoracic surgeries. A major boost to the development of automatic artificial ventilators occurred in 1952 when there was a polio epidemic in Denmark. They were primarily body enclosing devices ${ }^{[1]}$ and iron lung devices. ${ }^{[2,3]}$ These early devices were based on the principle of negative pressure ventilation. The limitations of usage of these mega-size ventilators together with a better understanding of the lung mechanics and physiology led to the development of positive pressure ventilation. By the first half of $20^{\text {th }}$ century, the focus of ventilators shifted from just providing ventilator support to the patient to treating oxygenation failure. The concept of positive pressure ventilation took a major leap with subsequent identification of acute respiratory distress syndrome (ARDS). ${ }^{[4]}$

\section{Modes of Ventilation}

In the $1950 \mathrm{~s}$ and $1960 \mathrm{~s}$, there were only two modes of ventilation used either in intensive care units (ICUs) or in operating room. They were pressure-limited ventilation and volume-regulated ventilation. All modes of mechanical ventilation were derived from one or a combination of these two base systems. In the initial days, ventilators were primarily volume-controlled modes because they delivered a preset tidal volume $\left(\mathrm{V}_{\mathrm{T}}\right)$ independently from the patient's lung mechanics. ${ }^{[5]}$ Conventionally, moderately high $\mathrm{V}_{\mathrm{T}}(10-12 \mathrm{~mL} / \mathrm{kg})$, low respiratory rates $(8-10$ breaths $/ \mathrm{min})$, inspiration to expiration ratio (1:2), slightly increased fraction of inspired oxygen $\left(\mathrm{FiO}_{2}\right)(30 \%-50 \%)$, and zero end-expiratory pressure were used.

The concept of intermittent mandatory ventilation was introduced in the 1970s to assist in weaning patients from ventilators which were later modified to allow for better synchronization and to prevent breath stacking. In the last few decades, the technical aspects of ventilators have dramatically improved with respect to better flow delivery, use of microprocessors, improved triggering, and development of newer modes of mechanical ventilation. Moreover, all these are available in the ventilators integrated into the anesthesia machine. Toward the end of surgery, when the patients are recovering from the effect of muscle relaxant, they are often ventilated with synchronized intermittent mandatory ventilation mode. Similarly, when a supraglottic airway is being used to provide anesthesia, pressure support mode or synchronized intermittent mandatory ventilation mode is used to augment the patient's spontaneous ventilation.

There is greater flexibility and safety in the ventilation of even critically ill patients undergoing surgery. Modes such as inverse ratio ventilation and dual modes such as pressure control with volume guarantee are now available on anesthesia ventilators. High-frequency jet ventilation used intraoperatively, e.g., during video-assisted thoracoscopic surgery, represents extension of critical care to the operating theater whereas surgeries performed on patients while on extracorporeal membrane oxygenation represents exactly the reverse.

\section{Respiratory Monitoring}

Monitoring of ventilation was mainly clinical three decades ago where the chest expansion, auscultation of breath sounds, and color of the lips, nail bed, and the surgical field were all that was possible to monitor. Present-day monitoring of respiration includes pulse oximetry, capnography, airway pressures, and ventilator graphics (flow-time, pressure-time, and volume-time scalars as well as the flow-volume and pressure-volume loops) complemented with arterial blood gas analysis as required.

\section{Ventilator-induced lung injury}

Intraoperative mechanical ventilation is typically focused on maintaining homeostasis. As the old adage goes, "First of all, do no harm," preventing injury to the surgical patient under anesthesia is equally important. One of the major concerns of mechanical ventilation is the development of ventilator-induced lung injury (VILI), which is caused by volutrauma and barotrauma resulting in an enhanced systemic inflammatory response with worsening oxygenation. VILI was 
identified in patients with acute lung injury (ALI) requiring mechanical ventilation. Subsequently, the possibility of it developing in patients undergoing routine general endotracheal anesthesia was studied. As an extension to the ARDS net study, ${ }^{[6,7]}$ Choi et al. compared the use of $\mathrm{V}_{\mathrm{T}}$ of $12 \mathrm{~mL} / \mathrm{kg}$ without positive end-expiratory pressure (PEEP) with $\mathrm{V}_{\mathrm{T}}$ of $6 \mathrm{~mL} / \mathrm{kg}$ with PEEP of $10 \mathrm{~cm} \mathrm{H}_{2} \mathrm{O}$ in patients undergoing major abdominal surgery. They found that the usage of large $\mathrm{V}_{\mathrm{T}}$ without PEEP caused systemic inflammation and lung injury in patients with no lung disease. ${ }^{[8]}$ It is now clear that the principles of intraoperative mechanical ventilation should be similar to that in the ICU setting because of the difficulty in diagnosing ALI/ARDS and the potential for multiple hits caused by intraoperative volutrauma. ${ }^{[9]}$

Postoperative pulmonary complications (PPCs) are known to be associated with longer hospital stays and higher long-term mortality rates. ${ }^{[10]}$ Certain intraoperative protective mechanical ventilation strategies have been defined to minimize the occurrence of VILI such as the rational use of the $\mathrm{FiO}_{2}, \mathrm{~V}_{\mathrm{T}}$, and PEEP. ${ }^{[1]}$ The latest parameter that is being evaluated is the driving pressure.

\section{Fraction of inspired oxygen}

Indiscriminate use of high $\mathrm{FiO}_{2}$ and its association with direct pulmonary toxicity, interstitial fibrosis, reabsorption atelectasis, and tracheobronchitis is well documented. ${ }^{[12]}$ Hence, it is recommended that the lowest possible $\mathrm{FiO}_{2}$ is used to prevent hypoxia and to avoid hyperoxia. Although there is no robust evidence to recommend an ideal $\mathrm{FiO}_{2}$ in surgical patients, a minimum possible $\mathrm{FiO}_{2}$ to maintain a peripheral arterial saturation $\left(\mathrm{SpO}_{2}\right)$ level above $92 \%$ is recommended in nonobese surgical patients with healthy lungs undergoing open abdominal surgery. ${ }^{[12]}$

\section{Tidal volume}

Historically, high $\mathrm{V}_{\mathrm{T}}$ values (up to $15 \mathrm{~mL} / \mathrm{kg}$ predicted body weight $[\mathrm{PBW}]$ ) were used intraoperatively to increase the end-expiratory lung volume and to reduce the incidence of atelectasis. ${ }^{[13]}$ In later years, it was found that usage of low $\mathrm{V}_{\mathrm{T}}$ values was associated with a reduction in lung injuries induced by mechanical ventilation and has been consistently recommended for pulmonary protection during the intraoperative period. ${ }^{[14]}$ Large randomized clinical trials have demonstrated that intraoperative ventilation with a $\mathrm{V}_{\mathrm{T}}$ of 6- $8 \mathrm{~mL} / \mathrm{kg}$ PBW prevents the development of PPC in patients undergoing elective surgery. ${ }^{[15,16]}$

\section{Positive end-expiratory pressure}

Current evidence shows that the use of PEEP can reduce atelectasis, improve compliance without increasing dead space, and maintain the end-expiratory volume in obese and nonobese patients under general anesthesia. ${ }^{[10]}$

\section{Driving pressure}

The stretch of lung produced by mechanical ventilation can produce stress and strain of the alveoli and consequent lung injury. ${ }^{[17,18]}$ The total increase in transpulmonary pressure due to the $\mathrm{V}_{\mathrm{T}}$ and PEEP represents the stress imposed on the lung. The distension obtained or the deformation of the lung (increase in lung volume above the resting volume) in response represents the strain on the lung. The volume increase due to PEEP can be termed static (as it is constant pressure throughout respiratory cycle) whereas that due to the $\mathrm{V}_{\mathrm{T}}$ is termed dynamic (as it changes during the respiratory cycle). PEEP can be beneficial if it recruits collapsed alveoli (lowers dynamic strain) and harmful if it overinflates them (increases dynamic strain). Driving pressure $(\Delta \mathrm{P})$ can be measured as plateau pressure minus PEEP. The plateau pressure depends on the respiratory system compliance (CRS). Studies demonstrate that higher driving pressures may worsen clinical outcome intraoperatively. ${ }^{[19,20]}$ It is also suggested that PEEP must be set to maximize respiratory system compliance to reduce the dynamic strain in all patients requiring mechanical ventilation during general anesthesia. ${ }^{[21,22]}$ However, a recent study has shown that the driving pressure may reflect changes in compliance only if the end-expiratory volume is less than the predicted functional residual capacity (FRC). If PEEP has overdistended the lung and the aerated volume exceeds FRC, monitoring driving pressure may not reflect changes in compliance. Thus, the authors' caution against the use of $\mathrm{C}_{\mathrm{RS}}$ and $\Delta \mathrm{P}$ as intraoperative monitoring tools during general anesthesia. ${ }^{[23]}$ The utility of monitoring driving pressure intraoperatively needs further studies.

In summary, with deeper understanding of physiology and availability of sophisticated devices, mechanical ventilation during general anesthesia has undergone a sea change from the simple automaticity of the anesthetist's hands to more precise ventilation with consequent improvement in outcome.

Vamsidhar Chamala, Anitha Nileshwar
Department of Anaesthesiology, Kasturba Medical College, Manipal Academy of
Higher Education, Manipal, Karnataka, India
Address for correspondence: Dr. Anitha Nileshwar,
Department of Anaesthesiology, Kasturba Medical College, Manipal Academy of
Higher Education, Manipal - 576 104, Karnataka, India.
E-mail: anitharshenoy@gmail.com

\section{References}

1. Jones AF. Inventor; Improvement in Vacuum Apparatus for Treating Diseases. U.S. Patent 44,198 A; 13 September, 1864.

2. Emerson JH, Loynes JA. The Evolution of Iron Lungs: Respirators of the Body-Encasing Type. Cambridge: J. H. Emerson \& Company; 1958.

3. Drinker P, Shaw LA. An apparatus for the prolonged administration of artificial respiration: I. A design for adults and children. J Clin Invest 1929;7:229-47.

4. Ashbaugh DG, Bigelow DB, Petty TL, Levine BE. Acute respiratory distress in adults. Lancet 1967;2:319-23.

5. Puri N, Puri V, Dellinger RP. History of technology in the intensive care unit. Crit Care Clin 2009;25:185-200, ix.

6. Acute Respiratory Distress Syndrome Network, Brower RG, Matthay MA, Morris A, Schoenfeld D, Thompson BT, et al. Ventilation with lower tidal volumes as compared with traditional tidal volumes for acute lung injury and the acute respiratory distress syndrome. N Engl J Med 2000;342:1301-8.

7. Petrucci N, Iacovelli W. Lung protective ventilation strategy for the 
acute respiratory distress syndrome. Cochrane Database Syst Rev 2007;(3):CD003844.

8. Choi G, Wolthuis EK, Bresser P, Levi M, van der Poll T, Dzoljic M, et al. Mechanical ventilation with lower tidal volumes and positive end-expiratory pressure prevents alveolar coagulation in patients without lung injury. Anesthesiology 2006;105:689-95.

9. Schultz MJ, Haitsma JJ, Slutsky AS, Gajic O. What tidal volumes should be used in patients without acute lung injury? Anesthesiology 2007; 106:1226-31.

10. Güldner A, Kiss T, Serpa Neto A, Hemmes SN, Canet J, Spieth PM, et al. Intraoperative protective mechanical ventilation for prevention of postoperative pulmonary complications: A comprehensive review of the role of tidal volume, positive end-expiratory pressure, and lung recruitment maneuvers. Anesthesiology 2015;123:692-713.

11. PROVE Network Investigators for the Clinical Trial Network of the European Society of Anaesthesiology, Hemmes SN, Gama de Abreu M, Pelosi P, Schultz MJ. High versus low positive end-expiratory pressure during general anaesthesia for open abdominal surgery (PROVHILO trial): A multicentre randomised controlled trial. Lancet 2014;384:495-503.

12. Girardis M, Busani S, Damiani E, Donati A, Rinaldi L, Marudi A, et al. Effect of conservative vs. conventional oxygen therapy on mortality among patients in an intensive care unit: The oxygen-ICU randomized clinical trial. JAMA 2016;316:1583-9.

13. Bendixen HH, Hedley-Whyte J, Laver MB. Impaired oxygenation in surgical patients during general anesthesia with controlled ventilation. A concept of atelectasis. N Engl J Med 1963;269:991-6.

14. Serpa Neto A, Hemmes SN, Barbas CS, Beiderlinden M, Biehl M, Binnekade JM, et al. Protective versus conventional ventilation for surgery: A systematic review and individual patient data meta-analysis. Anesthesiology 2015;123:66-78.

15. Severgnini P, Selmo G, Lanza C, Chiesa A, Frigerio A, Bacuzzi A, et al. Protective mechanical ventilation during general anesthesia for open abdominal surgery improves postoperative pulmonary function. Anesthesiology 2013;118:1307-21.

16. Futier E, Constantin JM, Paugam-Burtz C, Pascal J, Eurin M, Neuschwander A, et al. A trial of intraoperative low-tidal-volume ventilation in abdominal surgery. N Engl J Med 2013;369:428-37.

17. Slutsky AS, Ranieri VM. Ventilator-induced lung injury. N Engl J Med 2013;369:2126-36.

18. Gattinoni L, Marini JJ, Pesenti A, Quintel M, Mancebo J, Brochard L, et al. The "baby lung" became an adult. Intensive Care Med 2016;42:663-73.
19. Neto AS, Hemmes SN, Barbas CS, Beiderlinden M, Fernandez-Bustamante A, Futier E, et al. Association between driving pressure and development of postoperative pulmonary complications in patients undergoing mechanical ventilation for general anaesthesia: A meta-analysis of individual patient data. Lancet Respir Med 2016;4:272-80.

20. Ladha K, Vidal Melo MF, McLean DJ, Wanderer JP, Grabitz SD, Kurth $\mathrm{T}$, et al. Intraoperative protective mechanical ventilation and risk of postoperative respiratory complications: Hospital based registry study. BMJ 2015;351:h3646.

21. Ferrando C, Soro M, Unzueta C, Suarez-Sipmann F, Canet J, Librero J, et al. Individualised perioperative open-lung approach versus standard protective ventilation in abdominal surgery (iPROVE): A randomised controlled trial. Lancet Respir Med 2018;6:193-203.

22. Ferrando C, Suarez-Sipmann F, Tusman G, León I, Romero E, Gracia E, et al. Open lung approach versus standard protective strategies: Effects on driving pressure and ventilatory efficiency during anesthesia - A pilot, randomized controlled trial. PLoS One 2017; 12:e0177399.

23. Grieco DL, Russo A, Romanò B, Anzellotti GM, Ciocchetti P, Torrini F, et al. Lung volumes, respiratory mechanics and dynamic strain during general anaesthesia. Br J Anaesth 2018;121:1156-65.

This is an open access journal, and articles are distributed under the terms of the Creative Commons Attribution-NonCommercial-ShareAlike 4.0 License, which allows others to remix tweak, and build upon the work non-commercially, as long as appropriate credit is given and the new creations are licensed under the identical terms.

\begin{tabular}{|l|l|}
\hline \multicolumn{2}{|c|}{ Access this article online } \\
\hline Quick Response Code: & Website: \\
& www.ijrconline.org \\
\cline { 2 - 2 } & \\
\hline
\end{tabular}

How to cite this article: Chamala V, Nileshwar A. Ventilation during anesthesia: From automatic human hand to intelligent machine!. Indian J Respir Care 2019;8:1-3. 